\title{
Final overall survival results of phase III GCIG CALYPSO trial of pegylated liposomal doxorubicin and carboplatin vs paclitaxel and carboplatin in platinum-sensitive ovarian cancer patients
}

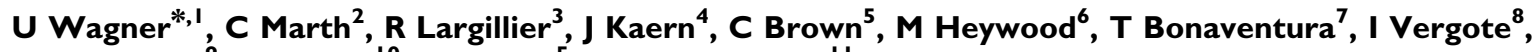 MC Piccirillo9, R Fossati' ${ }^{10}, \mathrm{~V}$ Gebski ${ }^{5}$ and EP Lauraine ${ }^{11}$}

'Department of Gynecology, Gynecologic Endocrinology and Oncology, University Hospital of Gießen and Marburg, Baldingerstrasse, 35043 Marburg, Germany; ${ }^{2}$ Department of Obstetrics \& Gynecology Medical University Innsbruck, Innsbruck, Austria; ${ }^{3}$ Centre Azuréen de Cancérologie, Mougins, France; ${ }^{4}$ Department of Gynecologic Oncology, The Norwegian Radium Hospital, Oslo, Norway; ${ }^{5}$ NHMRC Clinical Trials Centre, Camperdown, New South Wales, Australia; ' Department of Gyn Oncology, Gordon \& Leslie Diamond Health Centre, Vancouver, British Columbia, Canada; ${ }^{7}$ Department of Medical Oncology, Newcastle Mater Misericordia Hospital, Newcastle, NSW, Australia; ${ }^{8}$ Department of Obstetrics and Gynaecology, University Hospital Leuven, Leuven Cancer Institute, Leuven, Belgium; ${ }^{9}$ Clinical Trials Unit, National Cancer Institute of Napoli, Napoli, Italy; ${ }^{10}$ Department of Oncology, Mario Negri Institute, Milan, Italy; "'Department of Medical Oncology, Université Paris Descartes, AP-HP, Hôpitaux Universitaires Paris Centre, Paris, France

BACKGROUND: The CALYPSO phase III trial compared CD (carboplatin-pegylated liposomal doxorubicin (PLD)) with CP (carboplatinpaclitaxel) in patients with platinum-sensitive recurrent ovarian cancer (ROC). Overall survival (OS) data are now mature.

METHODS: Women with ROC relapsing $>6$ months after first- or second-line therapy were randomised to CD or CP for six cycles in this international, open-label, non-inferiority trial. The primary endpoint was progression-free survival. The OS analysis is presented here.

RESULTS: A total of 976 patients were randomised (467 to CD and 509 to CP). With a median follow-up of 49 months, no statistically significant difference was observed between arms in OS (hazard ratio $=0.99$ (95\% confidence interval 0.85, I. I6); log-rank $P=0.94$ ). Median survival times were 30.7 months (CD) and 33.0 months (CP). No statistically significant difference in OS was observed between arms in predetermined subgroups according to age, body mass index, treatment-free interval, measurable disease, number of lines of prior chemotherapy, or performance status. Post-study cross-over was imbalanced between arms, with a greater proportion of patients randomised to CP receiving post-study PLD (68\%) than patients randomised to CD receiving post-study paclitaxel (43\%; $P<0.001)$.

CONCLUSION: Carboplatin-PLD led to delayed progression and similar OS compared with carboplatin-paclitaxel in platinum-sensitive ROC.

British Journal of Cancer (2012) 107, 588-59I. doi:I0.1038/bjc.2012.307 www.bjcancer.com

Published online 26 July 2012

(C) 2012 Cancer Research UK

Keywords: CALYPSO; pegylated liposomal doxorubicin; recurrent ovarian cancer; overall survival; platinum-sensitive; carboplatin; paclitaxel

In patients with recurrent ovarian cancer (ROC) that is platinumsensitive (relapsing $\geqslant 6$ months following prior treatment), an analysis of International Collaborative Ovarian Neoplasm (ICON) and Arbeitsgemeinschaft Gynäkologische Onkologie Studiengruppe Ovarialkarzinom (AGO-OVAR) phase III trials demonstrated improved overall survival (OS) with paclitaxel-carboplatin combination chemotherapy compared with carboplatin alone

*Correspondence: Professor Dr U Wagner; E-mail: uwe.wagner@med. uni-marburg.de

This study was previously presented at the 201I American Society of Clinical Oncology Annual Meeting: Marth C, Alexandre J, Hanker LC, et al. Pegylated liposomal doxorubicin and carboplatin (C-PLD) versus paclitaxel and carboplatin (C-P) in platinum-sensitive ovarian cancer (OC) patients (pts): Treatment at recurrence and overall survival (OS) final analysis from CALYPSO phase III GCIG trial. J Clin Oncol 29: 20I I (suppl; abstr 5052).

Received 28 March 2012; revised 13 June 2012; accepted 18 June 2012; published online 26 July 2012 (hazard ratio (HR), 0.82; 95\% confidence interval (CI), 0.69-0.97; $P=0.02$ ) (Parmar et al, 2003; Pfisterer et al, 2006). In a phase II trial of similar design, González-Martín et al (2005) also showed prolonged survival with paclitaxel-carboplatin (HR 0.31; 95\% CI, $0.14,0.68 ; P=0.0021)$. However, this combination is accompanied by a significant toxicity, including peripheral neuropathy, neutropenia, and alopecia. Furthermore, additional survival improvement for this patient population remains an important goal, with a 2-year survival rate of $57 \%$ observed in the paclitaxelcarboplatin arm of the ICON/AGO-OVAR trials.

Pegylated liposomal doxorubicin (PLD) has been shown an active drug in platinum-sensitive ROC and has a better toxicity profile than paclitaxel. An earlier study evaluating PLD monotherapy $v s$ topotecan demonstrated significantly improved progression-free survival (PFS) and OS in patients receiving PLD (Gordon et al, 2001, 2004). The survival benefit was more pronounced for patients with partially sensitive ROC (treatmentfree interval (TFI) of $>6$ months and $<12$ months). In these patients, the HR for OS was 1.58 compared with 1.15 for those with 
a TFI $>12$ months (Gordon et al, 2004). The Groupe d'Investigateurs Nationaux pour l'Étude des Cancers Ovariens et du sein (GINECO) has explored the combination of PLD and carboplatin in a phase II trial. The OS was 21 months in patients with partially platinum sensitive ROC and 36 months in fully sensitive ROC (Ferrero et al, 2007). Using the same regimen in a prospective, consecutive cohort, an OS of 30 months was observed in 32 partially sensitive patients and 54 months in 49 fully sensitive patients (Weber et al, 2009).

CALYPSO, a large international randomised Gynecologic Cancer Intergroup (GCIG) phase III trial, compared PLD plus carboplatin (CD) to paclitaxel plus carboplatin (CP) in 976 patients with platinum-sensitive ROC (Pujade-lauraine et al, 2010). The primary endpoint was the non-inferiority of CD relative to CP in PFS. Patients receiving $C D$ experienced a statistically significant improvement in PFS compared with patients receiving CP ( $\mathrm{HR}=0.82$ (95\% CI, 0.72, $0.94) ; P=0.005)$. Overall severe non-haematologic toxicity $(28.4 \% v s$ $36.8 \% ; P=0.001)$ occurred less frequently in the $\mathrm{CD}$ arm, making this regimen an attractive option with a favourable therapeutic index for patients with platinum-sensitive ROC.

Overall survival data are now mature from CALYPSO. The current analysis investigates whether the observed PFS improvement translated into an OS benefit for patients receiving $C D$ compared with CP for platinum-sensitive ROC.

\section{PATIENTS AND METHODS}

The patients, methods, and design of CALYPSO were previously reported (Pujade-Lauraine et al, 2010). Briefly, patients had ovarian cancer that recurred $>6$ months after first- or second-line platinumbased chemotherapy and had received a taxane. Treatment consisted of carboplatin (C) AUC 5 plus PLD $30 \mathrm{mg} \mathrm{m}^{-2}$ (CD) on day 1 every 4 weeks or C AUC 5 plus paclitaxel (P) $175 \mathrm{mg} \mathrm{m}^{-2}$ (CP) on day 1 every 3 weeks. Patients received six cycles in the absence of disease progression or unacceptable toxicity, with additional cycles allowed for patients experiencing response or stable disease.

\section{Randomisation and masking}

CALYPSO was an international randomised, phase III, open-label, multicenter trial. Randomisation was performed in permuted blocks with stratification by measurable disease (yes vs no), TFI from last chemotherapy (6-12 vs $>12$ months), and centre.

\section{Statistical analysis}

The study design was that of non-inferiority for PFS. The secondary endpoint was OS and analysed using a log-rank test. Exploratory analysis of baseline characteristics was performed with Cox regression and pre-specified subgroups were assessed for differing treatment effects.

\section{RESULTS}

A total of 976 patients were randomised between April 2005 and September 2007 (467 to CD and 509 to CP). Baseline patient and disease characteristics were balanced between arms (Table 1). The majority of patients had FIGO stage III/IV disease and had received only one line of prior treatment. Two-thirds of the patients had a TFI of $>12$ months since prior chemotherapy. Further details of patient characteristics are reported elsewhere (Pujade-Lauraine et al, 2010).

In a prior analysis, PFS was statistically significantly prolonged in the $\mathrm{CD}$ arm $(\mathrm{HR}=0.82(95 \% \mathrm{CI}, 0.72,0.94) ; P=0.005)$ based on a median follow-up of 22 months (Pujade-Lauraine et al, 2010). Median PFS times were 9.4 months in the CP arm and 11.3 months in the CD arm.
Table I Baseline characteristics

\begin{tabular}{|c|c|c|}
\hline & $\begin{array}{c}C D \\
n=466\end{array}$ & $\begin{array}{c}\text { CP } \\
n=509\end{array}$ \\
\hline & \multicolumn{2}{|c|}{$n(\%)$} \\
\hline Median age, years & 60.5 & 61.0 \\
\hline \multicolumn{3}{|l|}{ ECOG performance status ${ }^{\mathrm{a}}$} \\
\hline 0 & $286(61)$ & $317(62)$ \\
\hline 1 & $159(34)$ & $164(32)$ \\
\hline 2 & $13(3)$ & $15(3)$ \\
\hline Primary disease site ovarian & $415(89)$ & $451(89)$ \\
\hline Papillary/serous histology & $334(72)$ & $366(72)$ \\
\hline \multicolumn{3}{|l|}{ Initial FIGO stage $\mathrm{a}^{\mathrm{a}}$} \\
\hline$|/| \mid$ & $52(\mid I)$ & $59(12)$ \\
\hline III/IV & $401(86)$ & $427(84)$ \\
\hline \multicolumn{3}{|c|}{ Number of previous therapy lines } \\
\hline I & $408(88)$ & $421(83)$ \\
\hline 2 & $58(12)$ & $87(17)$ \\
\hline Prior taxane & $462(99)$ & $500(99)$ \\
\hline \multicolumn{3}{|c|}{ Median interval since prior therapy } \\
\hline $6-12$ months & $162(35)$ & $182(36)$ \\
\hline$>12$ months & $304(65)$ & $326(64)$ \\
\hline \multicolumn{3}{|l|}{ Measurable disease } \\
\hline Yes & $28 \mid(60)$ & $321(63)$ \\
\hline No & $185(39)$ & $188(37)$ \\
\hline \multicolumn{3}{|l|}{ Tumour size } \\
\hline$<5 \mathrm{~cm}$ & $377(81)$ & $419(82)$ \\
\hline$\geqslant 5 \mathrm{~cm}$ & $89(19)$ & $90(18)$ \\
\hline \multicolumn{3}{|l|}{ Number of sites of recurrence } \\
\hline I & $217(47)$ & $245(48)$ \\
\hline$>1$ & $249(53)$ & $264(52)$ \\
\hline
\end{tabular}

Abbreviations: $\mathrm{CD}=$ carboplatin-pegylated liposomal doxorubicin; $\mathrm{CP}=$ carboplatin-

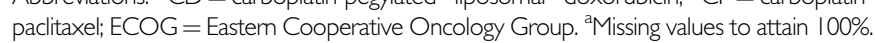

In this analysis, the median follow-up is 49 months (range 0-68 months) with a total of 663 deaths: 346 in the CP arm and 317 in the $\mathrm{CD}$ arm. The hazard ratio for CP:CD was 0.99 (95\% CI, 0.85, 1.16), which was not statistically significant (log-rank $P=0.94$; Figure 1). Median survival times were 30.7 months in the CD arm and 33.0 months in the CP arm.

Post-study therapy was received by $90 \%$ of patients in either arm of CALYPSO. The majority of patients (69\%) received two or more lines (Table 2). Analysis of cross-over between the arms demonstrated an imbalance. The proportion of patients randomised to CP who received PLD as post-study therapy (68\%) was higher than the proportion of patients randomised to $C D$ who received paclitaxel as post-study therapy $(43 \% ; P<0.001)$.

Factors that significantly correlate to survival were age, TFI, ECOG PS, residual disease, CA125, measurable disease, longest lesion size, and disease sites in univariate analyses. In multivariate analysis, TFI $\geqslant 12$ months, ECOG PS $0, \mathrm{CA} 125<100 \mathrm{U} \mathrm{ml}^{-1}$, nonmeasurable disease, and one involved disease site remained significantly correlated to survival (Table 3 ).

For a priori subgroups age, body mass index, TFI, measurable disease, number of lines of prior chemotherapy, and ECOG performance status, univariate proportional hazards regression for treatment did not show any statistically significant effect (Table 4).

\section{DISCUSSION}

CALYPSO is the largest clinical trial in ROC, enroling 976 patients. Designed as a non-inferiority trial, CALYPSO demonstrated that 


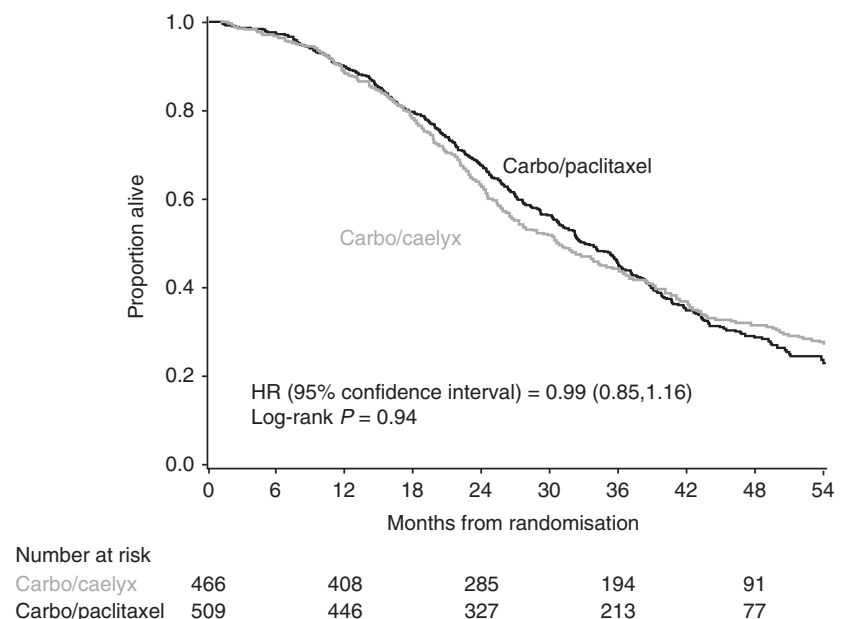

Figure I Overall survival in patients receiving carboplatin-paclitaxel or carboplatin-PLD for platinum-sensitive recurrent ovarian cancer. Abbreviation: PLD, pegylated liposomal doxorubicin.

Table 2 Number of post-study therapy lines and cross-overs

\begin{tabular}{lc}
\hline Treatment & Patients (\%) \\
\hline Number of lines & 10 \\
0 & 21 \\
1 & 25 \\
2 & 21 \\
3 & 13 \\
4 & 10 \\
$5-11$ & 69 \\
2 or more lines & \\
& \\
Cross-overs & \\
CP arm & 68 \\
CD arm & 43 \\
\hline
\end{tabular}

Abbreviations: $\mathrm{CD}=$ carboplatin-pegylated liposomal doxorubicin; $\mathrm{CP}=$ carboplatinpaclitaxel. ${ }^{a} P<0.001$ for comparison between arms.

Table 3 Multivariate cox regression model of overall survival $(N=959)$

\begin{tabular}{|c|c|c|c|c|}
\hline Factors & $N$ & HR & $95 \% \mathrm{Cl}$ & $P$-value \\
\hline \multicolumn{5}{|c|}{ TFl, months } \\
\hline $6-12$ & 342 & & & \\
\hline$\geqslant 12$ & 617 & 0.50 & $0.43,0.59$ & $<0.001$ \\
\hline \multicolumn{5}{|l|}{ ECOG PS } \\
\hline $0^{a}$ & 615 & & & \\
\hline$\geqslant 1$ & 344 & 1.37 & $1.17,1.60$ & $<0.001$ \\
\hline \multicolumn{5}{|c|}{$\mathrm{CA} / 25, \mathrm{Uml}^{-1}$} \\
\hline$<100$ & 316 & & & \\
\hline$\geqslant 100$ & 643 & 1.78 & $1.49,2.14$ & $<0.001$ \\
\hline \multicolumn{5}{|c|}{ Measurable disease/longest lesion, $\mathrm{mm}$} \\
\hline No & 361 & & & \\
\hline$\leqslant 50$ & 422 & 1.28 & $1.04,1.57$ & 0.02 \\
\hline$>50$ & 176 & 1.78 & $1.40,2.26$ & $<0.001$ \\
\hline \multicolumn{5}{|c|}{ Involved disease sites } \\
\hline I & 453 & & & \\
\hline$>1$ & 506 & 1.26 & $1.05,1.52$ & 0.014 \\
\hline
\end{tabular}

Abbreviations: $\mathrm{Cl}=$ confidence interval; ECOG PS = Eastern Cooperative Oncology Group performance status; $\mathrm{HR}=$ hazard ratio; $\mathrm{TFI}=$ treatment-free interval. ${ }^{\text {aT }}$ This category includes any unknown or not applicable values.
Table 4 Overall survival by treatment arm in pre-defined patient subgroups

\begin{tabular}{|c|c|c|c|c|c|c|}
\hline & \multicolumn{2}{|c|}{$\mathbf{N}$} & \multicolumn{4}{|c|}{ Univariate cox regression model } \\
\hline & CD & $\mathbf{C P}$ & HR & $95 \% \mathrm{Cl}$ & $\begin{array}{c}\text { Subgroup } \\
P \text {-value }\end{array}$ & $\begin{array}{c}\text { Interaction } \\
P \text {-value }\end{array}$ \\
\hline \multicolumn{7}{|l|}{ Age, years } \\
\hline$<70$ & 395 & 423 & 0.98 & $0.83,1.16$ & 0.80 & 0.61 \\
\hline$\geqslant 70$ & 71 & 86 & 1.10 & $0.76,1.58$ & 0.62 & \\
\hline \multicolumn{7}{|c|}{$\mathrm{BMl}, \mathrm{kg} \mathrm{m}^{-2}$} \\
\hline$<30$ & 378 & 399 & 1.00 & $0.85,1.19$ & 0.98 & 0.74 \\
\hline$\geqslant 30$ & 88 & 110 & 0.95 & $0.67,1.35$ & 0.76 & \\
\hline \multicolumn{7}{|c|}{ TFI, months } \\
\hline $6-12$ & 161 & 183 & 1.01 & $0.80,1.28$ & 0.92 & 0.86 \\
\hline$\geqslant 12$ & 305 & 326 & 0.99 & $0.81,1.21$ & 0.90 & \\
\hline \multicolumn{7}{|c|}{ Measurable disease } \\
\hline No & 137 & 138 & 0.88 & $0.65,1.21$ & 0.56 & 0.31 \\
\hline Yes & 329 & 371 & 1.07 & $0.90,1.27$ & 0.47 & \\
\hline \multicolumn{7}{|c|}{ Number of prior lines } \\
\hline । & 408 & 418 & 0.99 & $0.84,1.17$ & 0.92 & 0.98 \\
\hline$\geqslant 2$ & 58 & 88 & 0.97 & $0.65,1.46$ & 0.74 & \\
\hline \multicolumn{7}{|l|}{ ECOG PS } \\
\hline 0 & 295 & 329 & 0.99 & $0.81,1.20$ & 0.92 & 0.95 \\
\hline$\geqslant 1$ & 171 & 180 & 0.99 & $0.78,1.27$ & 0.95 & \\
\hline
\end{tabular}

Abbreviations: $\mathrm{BMI}=$ body mass index; $\mathrm{CD}=$ carboplatin-pegylated liposomal doxorubicin; $\mathrm{Cl}=$ confidence interval; $\mathrm{CP}=$ carboplatin-paclitaxel; $\mathrm{ECOG} \mathrm{PS}=$ Eastern Cooperative Oncology Group performance status; $H R=$ hazard ratio;

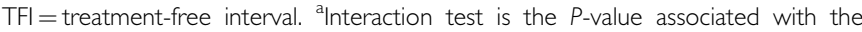
interaction term in the Cox regression model containing treatment effect, subgroup variable, and their interaction.

CD was not only non-inferior to CP in PFS but was also superior $(\mathrm{HR}=0.82, P=0.005)$ in patients with platinum-sensitive ROC. Furthermore, $C D$ was associated with less carboplatin hypersensitivity, peripheral neuropathy, prolonged neutropenia, and alopecia. Toxicities observed more commonly with CD were mucositis, nausea and vomiting, and palmar-plantar erythrodysesthesia. These toxicities were generally low-grade, short-term, and manageable (Pujade-Lauraine et al, 2010; Joly et al, 2011). Taken together, $\mathrm{CD}$ emerged as a welcome option for treating platinum-sensitive ROC that exhibited a favourable therapeutic index.

Several analyses of CALYPSO have been undertaken (Gladieff et al, 2011; Joly et al, 2011; Kurtz et al, 2011; Lee et al, 2011). In the current analysis, OS of CD and CP were evaluated. In the overall population, OS was similar between arms $(\mathrm{HR}=0.99$; log-rank $P=0.94$ ). Median survival was 30.7 months in the CD arm. Prior investigations of this regimen have shown median survival times of 25-39 months (Ferrero et al, 2007; Weber et al, 2009; Bafaloukos et al, 2010). Median survival in the $\mathrm{CP}$ arm was 33.0 months; historical data have shown 29 months (Parmar et al, 2003; Bafaloukos et al, 2010).

When analysed by patient subgroups according to age, BMI, TFI, measurable disease, number of prior therapy lines, and ECOG PS, no statistically significant differences emerged between treatment arms in any of the subgroups. Notable was the lack of difference between arms regardless of TFI. The HR for OS in the partially platinum-sensitive subgroup (TFI 6-12 months) was 1.01 (95\% CI, $0.80,1.28 ; P=0.92$ ), whereas the HR for OS in the sensitive subgroup (TFI > 12 months) was 0.99 (95\% CI, 0.81, 1.21; $P=0.90)$. These results lie in contrast to the study of monotherapy 
PLD $v s$ topotecan, which showed a more pronounced survival benefit for PLD relative to topotecan in patients with partially platinum-sensitive disease (Gordon et al, 2004).

An imbalance in post-study therapy may have affected OS and mitigated the PFS benefit observed with CD. Post-study PLD was received by $68 \%$ of patients in the $\mathrm{CP}$ arm, while post-study paclitaxel was administered to $43 \%$ of patients in the CD arm $(P<0.001)$.

The results of CALYPSO demonstrate that carboplatin-PLD offers an attractive option as compared with the standard of care, carboplatin-paclitaxel, for the treatment of platinum-sensitive ROC. Patients receiving carboplatin-PLD experienced delayed progression, similar survival, less carboplatin hypersensitivity, and less peripheral neuropathy, a toxicity associated with longterm sequelae, compared with patients receiving carboplatinpaclitaxel.

\section{REFERENCES}

Bafaloukos D, Linardou H, Aravantinos G, Papadimitriou C, Bamias A, Fountzilas G, Kalofonos HP, Kosmidis PE, Makatsoris T, Samantas E, Briasoulis E, Christodoulou C, Papakostas P, Pectasides D, Dimopoulos AM (2010) A randomized phase II study of carboplatin plus pegylated liposomal doxorubicin versus carboplatin plus paclitaxel in platinum sensitive ovarian cancer patients: a Hellenic Cooperative Oncology Group study. BMC Med 8: 3

Ferrero JM, Weber B, Geay JF, Lepille D, Orfeuvre H, Combe M, Mayer F, Leduc B, Bourgeois H, Paraiso D, Pujade-Lauraine E (2007) Second-line chemotherapy with pegylated liposomal doxorubicin and carboplatin is highly effective in patients with advanced ovarian cancer in late relapse: a GINECO phase II trial. Ann Oncol 18: 263-268

Gladieff L, Ferrero A, De Rauglaudre G, Brown C, Vasey P, Reinthaller A, Pujade-Lauraine E, Reed N, Lorusso D, Siena S, Helland H, Elit L, Mahner S (2011) Carboplatin and pegylated liposomal doxorubicin versus carboplatin and paclitaxel in partially platinum-sensitive ovarian cancer patients: results from a subset analysis of the CALYPSO phase III trial. Ann Oncol 23: 1185-1189

González-Martín AJ, Calvo E, Bover I, Rubio MJ, Arcusa A, Casado A, Ojeda B, Balañá C, Martínez E, Herrero A, Pardo B, Adrover E, Rifá J, Godes MJ, Moyano A, Cervantes A (2005) Randomized phase II trial of carboplatin versus paclitaxel and carboplatin in platinumsensitive recurrent advanced ovarian carcinoma: a GEICO (Grupo Español de Investigación en Cáncer de Ovario) study. Ann Oncol 16: 749-755

Gordon A, Fleagle J, Guthrie D, Parkin D, Gore M, Lacave A (2001) Recurrent epithelial ovarian carcinoma: a randomized phase III study of pegylated liposomal doxorubicin versus topotecan. J Clin Oncol 19: 3312-3322

Gordon A, Tonda M, Sun S, Rackoff W, Doxil Study 30-49 Investigators (2004) Long-term survival advantage for women treated with pegylated liposomal doxorubicin compared with topotecan in a phase 3 randomized study of recurrent and refractory epithelial ovarian cancer. Gynecol Oncol 95: 1-8

Joly F, Ray-Coquard I, Fabbro M, Donoghoe M, Boman K, Sugimoto A, Vaughan M, Reinthaller A, Vergote I, Ferrandina G, Dell'Anna T, Huober J, Pujade-Lauraine E (2011) Decreased hypersensitivity reactions with carboplatin-pegylated liposomal doxorubicin compared

\section{ACKNOWLEDGEMENTS}

We acknowledge the women who participated in this study as well as the investigators and their staff, Phillips Gilmore and Laura Evans for editing and technical assistance in preparation of the manuscript. Research support provided by Merck, formerly Schering-Plough Corporation.

\section{Conflict of interest}

The authors declare no conflict of interest.

\section{Participant Institutions}

AGO; AGO-Austria; GINECO; NSGO; Stat; NCI-CTG; ANZGOG; EORTC; MITO; MANGO; Stat; GINECO

to carboplatin-paclitaxel combination: Analysis from the GCIG CALYPSO relapsing ovarian cancer trial. Gynecol Oncol 122: 226-232

Kurtz JE, Kaminsky MC, Floquet A, Veillard AS, Kimmig R, Dorum A, Elit L, Buck M, Petru E, Reed N, Scambia G, Varsellona N, Brown C, Pujade-Lauraine E, Gynecologic Cancer Intergroup (2011) Ovarian cancer in elderly patients: carboplatin and pegylated liposomal doxorubicin versus carboplatin and paclitaxel in late relapse: a Gynecologic Cancer Intergroup (GCIG) CALYPSO sub-study. Ann Oncol 22: 2417-2423

Lee CK, Friedlander M, Brown C, Gebski VJ, Georgoulopoulos A, Vergote I, Pignata S, Donadello N, Schmalfeldt B, Delva R, Mirza MR, Sauthier P, Pujade-Lauraine E, Lord SJ, Simes RJ (2011) Early decline in cancer antigen 125 as a surrogate for progression-free survival in recurrent ovarian cancer. J Natl Cancer Inst 103: 1338-1342

Parmar MK, Ledermann JA, Colombo N, du Bois A, Delaloye JF, Kristensen GB, Wheeler S, Swart AM, Qian W, Torri V, Floriani I, Jayson G, Lamont A, Tropé C, ICON and AGO Collaborators (2003) Paclitaxel plus platinum-based chemotherapy versus conventional platinum-based chemotherapy in women with relapsed ovarian cancer: the ICON4/ AGO-OVAR-2.2 trial. Lancet 361: 2099-2106

Pfisterer J, Plante M, Vergote I, du Bois A, Hirte H, Lacave AJ, Wagner U, Stähle A, Stuart G, Kimmig R, Olbricht S, Le T, Emerich J, Kuhn W, Bentley J, Jackisch C, Lück HJ, Rochon J, Zimmermann AH, Eisenhauer E, AGO-OVAR, NCIC CTG, EORTC GCG (2006) Gemcitabine plus carboplatin compared with carboplatin in patients with platinum-sensitive recurrent ovarian cancer: an intergroup trial of the AGO-OVAR, the NCIC CTG, and the EORTC GCG. J Clin Oncol 24: 4699-4707

Pujade-Lauraine E, Wagner U, Aavall-Lundqvist E, Gebski V, Heywood M, Vasey PA, Volgger B, Vergote I, Pignata S, Ferrero A, Sehouli J, Lortholary A, Kristensen G, Jackisch C, Joly F, Brown C, Le Fur N, du Bois A (2010) Pegylated liposomal doxorubicin and carboplatin compared with paclitaxel and carboplatin for patients with platinumsensitive ovarian cancer in late relapse. J Clin Oncol 28: 3323-3329

Weber B, Lortholary A, Mayer F, Bourgeois H, Orfeuvre H, Combe M, Platini C, Cretin J, Fric D, Paraiso D, Pujade-Lauraine E (2009) Pegylated liposomal doxorubicin and carboplatin in late-relapsing ovarian cancer: a GINECO group phase II trial. Anticancer Res 29: 4195-4200

This work is published under the standard license to publish agreement. After 12 months the work will become freely available and the license terms will switch to a Creative Commons Attribution-NonCommercial-Share Alike 3.0 Unported License. 